\title{
Comparison of different retrieval techniques for melt ponds on Arctic sea ice from Landsat and MODIS satellite data
}

\author{
Anja RÖSEL, Lars KALESCHKE \\ Institute of Oceanography, University of Hamburg, Bundesstrasse 53, D-20146 Hamburg, Germany \\ E-mail: anja.roesel@zmaw.de
}

\begin{abstract}
Melt ponds are regularly observed on the surface of Arctic sea ice in late spring and summer. They strongly reduce the surface albedo and accelerate the decay of Actic sea ice. Until now, only a few studies have looked at the spatial extent of melt ponds on Arctic sea ice. Knowledge of the melt-pond distribution on the entire Arctic sea ice would provide a solid basis for the parameterization of melt ponds in existing sea-ice models. Due to the different spectral properties of snow, ice and water, a multispectral sensor such as Landsat 7 ETM+ is generally applicable for the analysis of distribution. An additional advantage of the ETM+ sensor is the very high spatial resolution $(30 \mathrm{~m})$. An algorithm based on a principal component analysis (PCA) of two spectral channels has been developed in order to determine the melt-pond fraction. PCA allows differentiation of melt ponds and other surface types such as snow, ice or water. Spectral bands 1 and 4 with central wavelengths at 480 and $770 \mathrm{~nm}$, respectively, are used as they represent the differences in the spectral albedo of melt ponds. A Landsat 7 ETM+ scene from 19 July 2001 was analysed using PCA. The melt-pond fraction determined by the PCA method yields a different spatial distribution of the ponded areas from that developed by others. A MODIS subset from the same date and area is also analysed. The classification of MODIS data results in a higher melt-pond fraction than both Landsat classifications.
\end{abstract}

\section{INTRODUCTION}

During the Arctic summer, the occurrence of melt ponds on Arctic sea ice is a periodic event. Melt ponds can cover up to $50 \%$ of the sea-ice area (Fetterer and Untersteiner, 1998). The albedo of a melt-pond-covered surface is substantially lower than that of a snow-covered or bare sea-ice surface. Typical wavelength-integrated albedo values for mature melt ponds are $0.2-0.3$. The values for younger melt ponds are higher and the value for fresh snow is 0.8 (Perovich, 1996). Melt processes on the surface decrease the overall averaged wavelength-integrated albedo of sea-ice area from $\sim 0.8$ to 0.5 (Perovich and Tucker, 1997). Melt ponds therefore play an important role in the ice-albedo feedback. Increasing temperatures and radiation during summer cause a reduction in the snow and ice extent, resulting in a decrease in the surface albedo and increasing the amount of sunlight absorbed by the surface. This in turn results in additional melting (Curry and others, 1995). Since the ice-albedo feedback has a significant influence on Earth's radiation balance, it is important to represent the fraction of melt ponds and albedo of the sea-ice-covered area in sea-ice and climate models.

In the Arctic region, melting of sea ice generally starts with the increasing solar radiation at the beginning of June. By mid-June, a significant fraction of pack ice is covered by melt ponds. Due to the increasing heat transmission in ponded areas, the ponds deepen and can even melt through the ice layer. Freezing starts in late August or early September and melt-pond fraction decreases (Fetterer and Untersteiner, 1998).

The Actic sea-ice cover is a small-fractioned inhomogeneous construct with surfaces varying from snow-covered ice, bare ice and melt ponds to open water; ice thickness ranges from zero (open water) to several metres (perennial level ice) to tens of metres (ridges). All these categories have different physical and optical properties. To determine the albedo changes of a larger area during the melt season, knowledge of the temporal and spatial variability of albedo in each of these ice categories is essential (Perovich and others, 2002b).

In the past, several field experiments have been conducted at different locations on the Arctic sea ice to study the spectral characteristics of melt ponds (Morassutti and LeDrew, 1996; Perovich and others, 2002b) as well as their distribution and size (S. El Naggar and others, http:// epic.awi.de/epic/Main?puid=18004; Perovich and others, 2002a, 2009). Knowledge of the spectral behaviour of ponded sea ice in comparison to bare or snow-covered sea ice was used by Tschudi and others $(1997,2001,2008)$ and Markus and others $(2002,2003)$ to determine the fraction of melt ponds from video imagery or satellite data.

In this study we develop a new technique based on principal component analysis (PCA) to identify the meltpond fraction from Landsat satellite data. The results are compared with a classification method based on tie points utilized by Markus and others (2003) and with analysis of a MODIS (Moderate Resolution Imaging Spectroradiometer) scene developed by Tschudi and others (2008). We discuss the feasibility of archiving an accurate and complete meltpond dataset throughout the seasonal cycle from Arctic seaice coverage.

\section{DATA}

Satellite data from Landsat 7, Terra and Aqua are used for this analysis. We selected an area in the northern Beaufort Sea. This area is covered by a Landsat scene acquired on 18 July 2001 (Fig. 1). In the corresponding true-colour subset (Fig. 2a) open water and individual ice floes can be distinguished by eye. The reflectivities of the ice fraction 


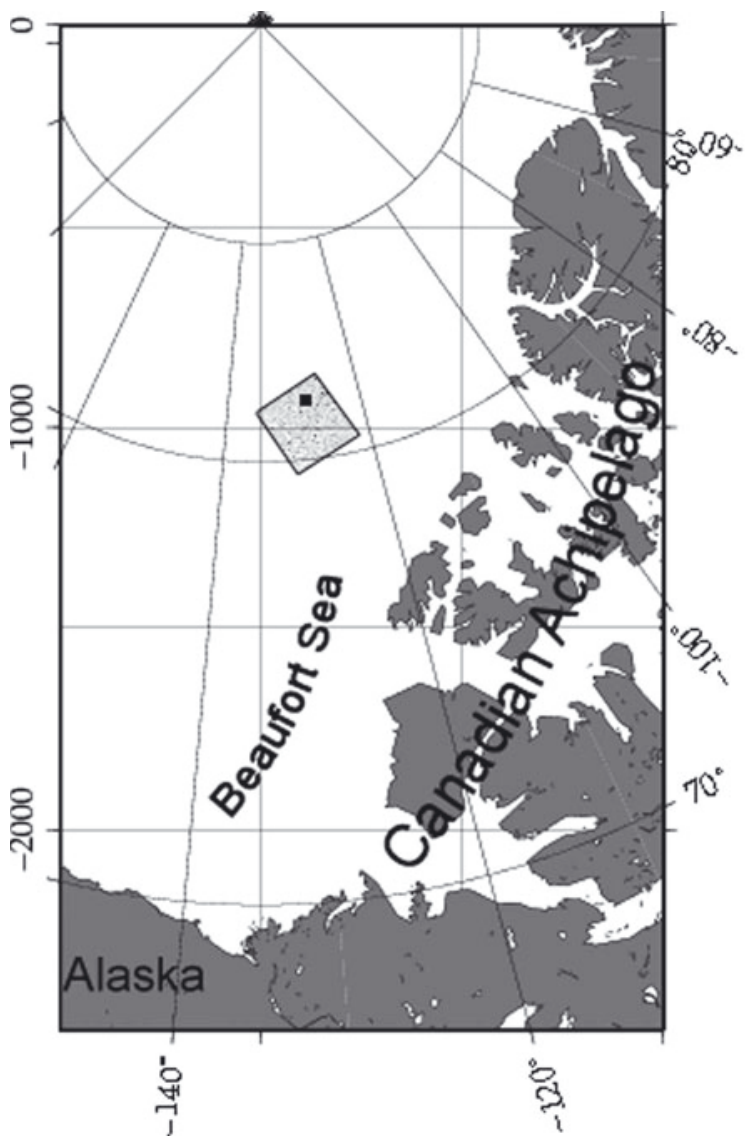

Fig. 1. Overview of the study area with the location of the selected Landsat 7 scene from 18 July 2001 and the subset area (black square) used for this study.

vary significantly. Snow-covered areas and/or bare white ice appear white. With the onset of melting and wetting of the snow and the ice surface, the colour spectrum varies across shades of grey and blue. Shallow melt ponds appear in light blue and develop from a green-blue tone to a darker blue colour when they have reached their full extent (Markus and others, 2002).

\section{Landsat 7 ETM+}

The ETM+ sensor on board the Landsat 7 satellite is an optomechanical multispectral scanner. The incoming reflected radiation passes through a telescope and is separated into seven spectral bands (reflective bands $1-5$ and 7 with $30 \mathrm{~m}$ spatial resolution and thermal band 6 with $60 \mathrm{~m}$ spatial resolution) and a panchromatic band (band 8) with $15 \mathrm{~m}$ spatial resolution. The received electromagnetic energy is converted into 256 discrete levels referred to as digital numbers (DNs). The revisit period of the satellite is 16 days. The inclination is $98.2^{\circ}$; this implies that acquisitions up to a latitude of $82^{\circ} \mathrm{N}$ are possible.

An extensive archive search of the US Geological Survey (USGS) Landsat archive was conducted to determine whether an overall seasonal coverage of the Arctic region would be possible with Landsat data. Unfortunately, the archive mainly covers coastal areas and not the open sea-ice area. The long revisit time of 16 days and the high number of cloudy days further limit the number of usable scenes.

The 8-bit Landsat sensor has severe problems with the saturation of the sensor over snow- and ice-covered surfaces.
The saturation of the sensor is also related to the solar elevation (Bindschadler and others, 2008); saturation problems increase with sun elevation. The Landsat 7 Enhanced Thematic Mapper Plus (ETM+) scene used in this study is located in the upper Beaufort Sea at $80-82^{\circ} \mathrm{N}$ from 18 July 2001 with a sun elevation angle of $28.7^{\circ}$. This dataset contains no saturated pixels. A $25 \mathrm{~km} \times 25 \mathrm{~km}$ subset of the full scene was analysed. Within this subset, training areas covering all necessary features such as open water (A), snow-covered ice (B) and two types of melt ponds (C and D) are visually identified from the true-colour composite (Fig. 2a). We assume that they reasonably represent the specific classes.

The ETM+ sensor is calibrated on a regular basis to maintain an accurate conversion of the DN values to the atsensor radiance. The calibration coefficients are included in the metadata file of each Landsat scene (NASA, http:// landsathandbook.gsfc.nasa.gov/handbook.html).

To calibrate the DN to absolute radiances, we use

$$
L(\lambda)=\frac{L_{\max }(\lambda)-L_{\min }(\lambda)}{255} \mathrm{DN}+L_{\min }(\lambda),
$$

where $L(\lambda)\left(\mathrm{W}\left(\mathrm{m}^{2} \mu \mathrm{m}\right)^{-1}\right)$ is the spectral at-sensor radiance and $L_{\max }(\lambda)$ and $L_{\min }(\lambda)$ are the spectral radiances for each band corresponding to $\mathrm{DN}=0$ or 255 , respectively. These have to be extracted for each band and are also included in the metadata file of each scene. To account for some between-scene variations, the radiance data were converted into planetary or top-of-the-atmosphere reflectance, $\alpha_{\mathrm{TOA}}$ (dimensionless), using

$$
\alpha_{\mathrm{TOA}}=\frac{\pi L(\lambda) d^{2}}{E_{\mathrm{S}}(\lambda) \cos \theta_{\mathrm{S}}},
$$

where $L(\lambda)$ is the spectral radiance at the aperture of the sensor, $d$ is the Earth-Sun distance in astronomical units, $E_{S}(\lambda)$ is the mean solar exoatmospheric irradiances $\left(\mathrm{W}\left(\mathrm{m}^{2} \mu \mathrm{m}\right)^{-1}\right)$ and $\theta_{\mathrm{S}}$ is the solar zenith angle in degrees $\left(90^{\circ}\right.$ - solar elevation angle). This information, as well as the Earth-Sun distance, the spectral band radiances and the solar spectral irradiances, is found in the Landsat 7 Science Data Users Handbook (NASA, http://landsathandbook.gsfc. nasa.gov/handbook.html).

Landsat data are delivered as GeoTiff files in Universal Transverse Mercator (UTM) map projection. For comparison with different sea-ice products, the data are reprojected to a polar stereographic grid according to the specifications of the US National Snow and Ice Data Center (NSIDC). For comparison with MODIS data, a grid size of $50 \mathrm{~m} \times 50 \mathrm{~m}$ spatial resolution was chosen and the data were resampled with a nearest-neighbour algorithm.

\section{MODIS}

The MODIS sensor is an optical instrument on board the Terra and Aqua platforms. The satellites were launched on 18 December 1999 and on 4 May 2002, respectively, in a sun-synchronous near-polar orbit at an altitude of $705 \mathrm{~km}$. Terra operates on a descending node with a mean equatorcrossing time of $1030 \mathrm{~h}$; Aqua operates on an ascending node with an equatorial overpass at $1330 \mathrm{~h}$. MODIS has 36 spectral bands ranging from 459 to $14385 \mathrm{~nm}$ with a spatial resolution of $250 \mathrm{~m} \times 250 \mathrm{~m}$ to $1 \mathrm{~km} \times 1 \mathrm{~km}$.

The MODIS Level 1B dataset used for this study was acquired on 18 July 2001 at $2315 \mathrm{~h}$ UTC. It contains calibrated and geolocated at-aperture radiances $\left(\mathrm{W}\left(\mathrm{m}^{2} \mu \mathrm{m}\right)^{-1}\right)$ and is 

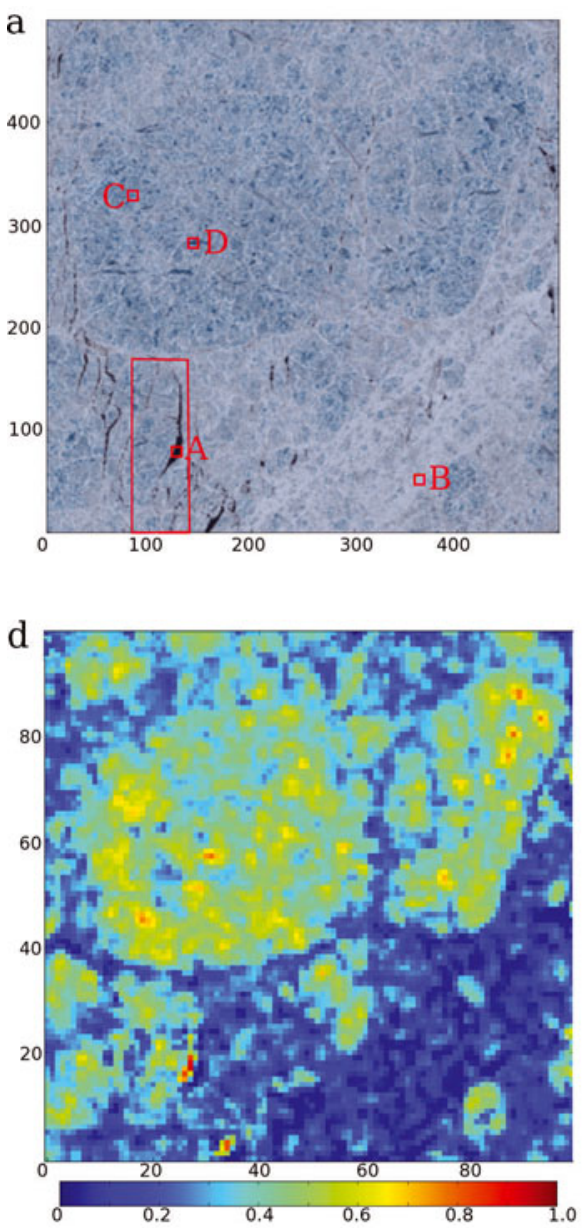
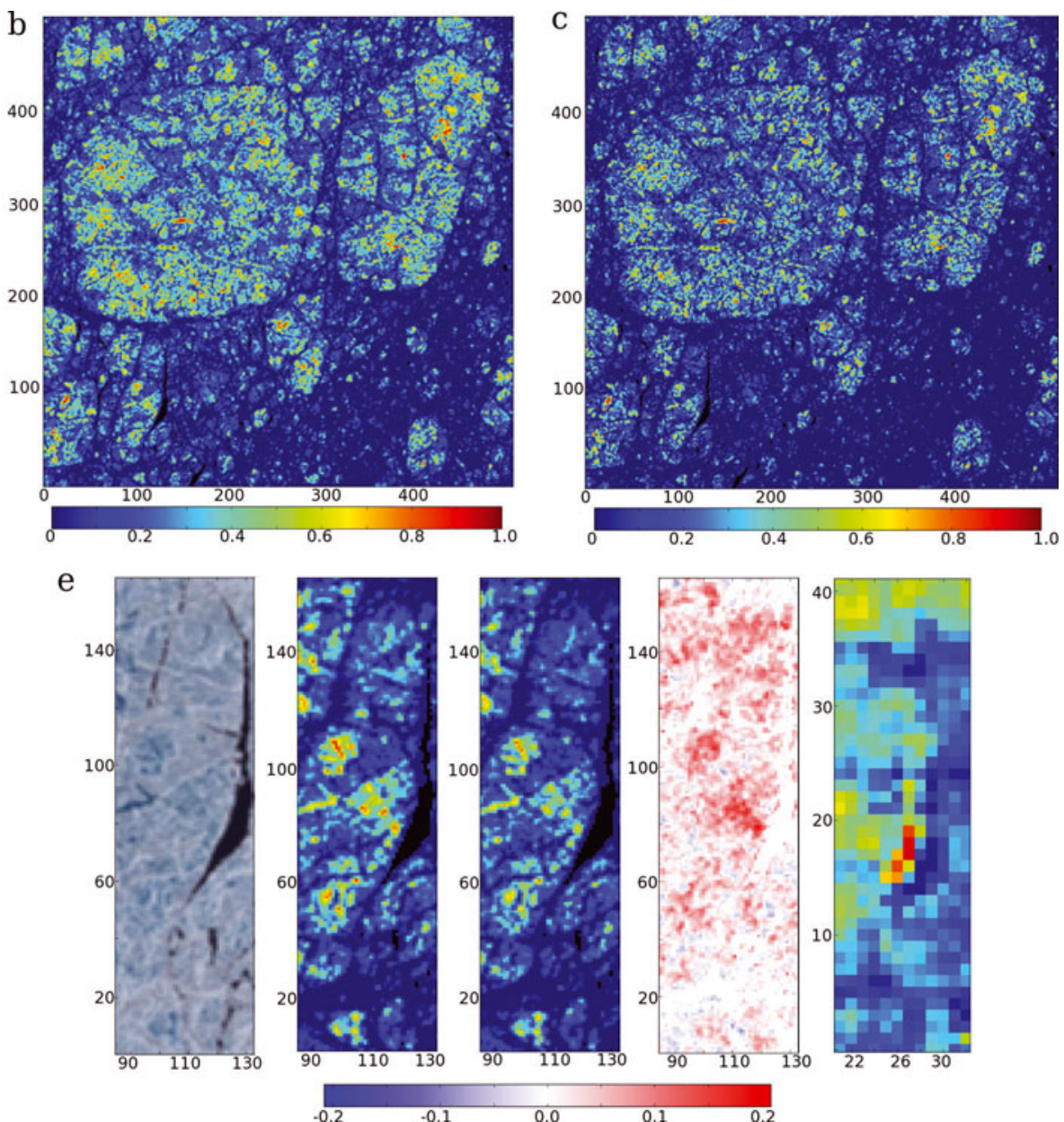

Fig. 2. (a) $25 \mathrm{~km} \times 25 \mathrm{~km}$ true-colour subset (band combination 3-2-1) from the Landsat scene displayed in Figure 1 with the selected training areas. This subset is used for all analysis. The red box shows the zoom for comparison (e). The coordinates are the gridcell numbers. (b) Melt-pond fraction of the Landsat subset determined with PCA. Black areas are identified as open water. (c) Melt-pond fraction of the Landsat subset determined using the method described by Markus and others (2003). Black areas are open water. (d) Melt-pond fraction determined from a MODIS subset of the same date and area. (e) From left to right: true-colour zoom; results of the PCA; results using the method of Markus and others (2003); differences between the two methods; and results from MODIS. The colour bar represents the values of the differences.

generated from MODIS level 1A data (http://modis.gsfc. nasa.gov/data/dataprod/). After removing the bow-tie effect, the MODIS data were also reprojected to the NSIDC polar stereographic grid and resampled with a nearest-neighbour algorithm to $250 \mathrm{~m} \times 250 \mathrm{~m}$ cell size. For this study, a $25 \times 25 \mathrm{~km}$ subset, covering the same coordinates as the Landsat subset, was used.

\section{METHODS}

The optical properties of ice and snow are a strong function of the wavelength of the incident solar radiation, $\lambda$ ( Fig. 3). Furthermore, the sea-ice albedo is affected by the incident solar zenith and azimuth angle and the viewing geometry of the satellite sensor (Warren, 1982). The influence of incidence and detector angles on the reflectance, expressed as bidirectional reflectance distribution function (BRDF), is the subject of future investigations and is therefore not considered further in this analysis.

The spectral- as well as the wavelength-integrated albedos of bare ice are fairly constant during the melting period. On the other hand, the albedo of ponded ice depends on the pond depth and varies throughout the melting period (Perovich and others, 2002b).

It is evident from Figure 3 that the curves for snowcovered ice, bare ice and melting bare ice demonstrate a smaller reduction in spectral albedo at longer wavelengths than the curves for two types of melt pond. At short wavelengths the reflectivity remains high compared to the longer wavelengths. These spectral differences can be used to separate melt ponds from bare or snow-covered ice.

To calculate the albedo value on a larger scale, the surface-based albedos are weighted with the fraction of their corresponding surface component (Perovich and others, 2009). The so-called areally averaged albedo, $\bar{\alpha}$, can be expressed:

$$
\bar{\alpha}=\alpha_{l} A_{l}+\alpha_{\mathrm{p}} A_{\mathrm{p}}+\alpha_{\mathrm{i}} a_{\mathrm{i}}
$$

where $A$ is the area fraction, $\alpha$ is the wavelength-integrated albedo and I, $\mathrm{p}$ and $\mathrm{i}$ represent values for leads, ponds and (bare) ice, respectively. Wavelength-integrated or total albedo values of different surface types have been extensively reported in the literature (e.g. Perovich, 1996; Perovich and others, 2002b; Tschudi and others, 2008). 


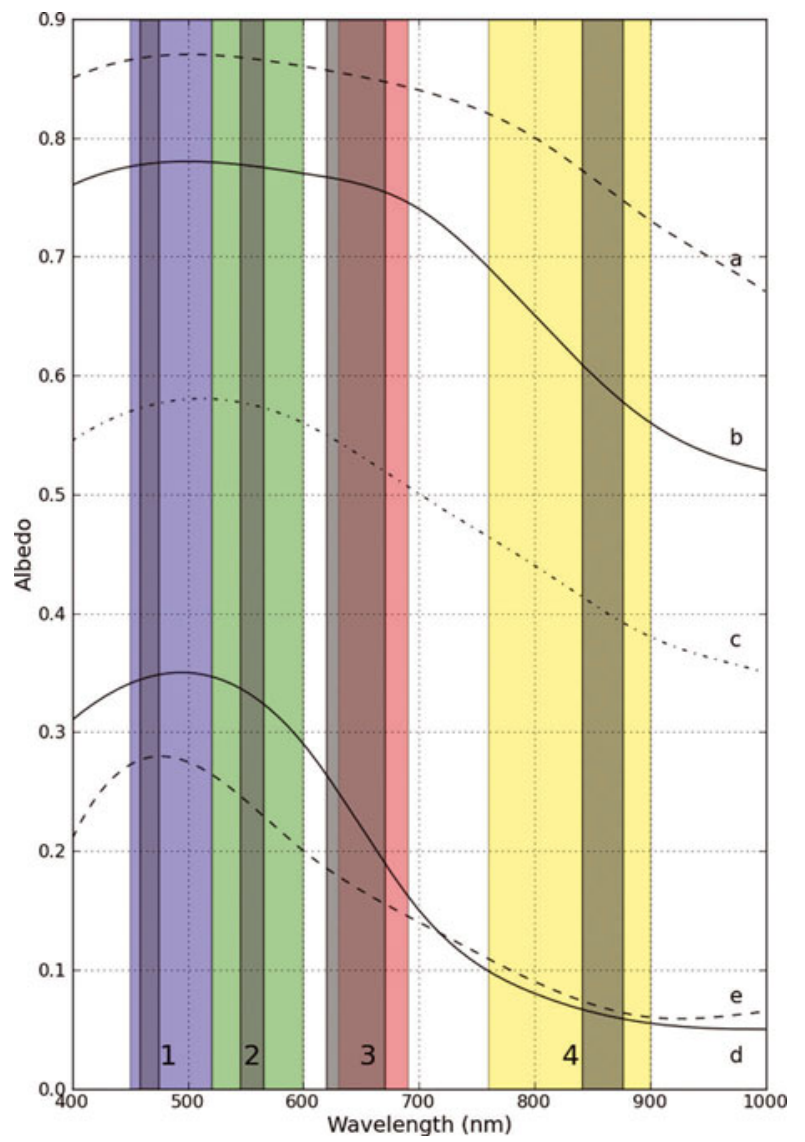

Fig. 3. Spectral albedos for different surface types on Arctic sea ice (values from Grenfell and Markut, 1977): (a) snow-covered ice; (b) cold bare ice; (c) melting bare ice; (d) young melt pond; and (e) mature melt pond. The coloured columns display the used Landsat bands; the dark-grey columns represent the corresponding MODIS bands.

Perovich and others (2009) report albedo values of 0.07 for leads/open water, of 0.65 for bare ice and 0.25 for melt ponds.

\section{Algorithm based on principal component analysis}

The spectral differences of melt ponds in comparison to bare or snow-covered sea ice and open water are used to detect melt ponds. From Figure 3 it is clear that these differences increase with longer wavelengths. We therefore used the spectral bands that could best resolve these differences. Figure 4 shows a two-dimensional (2-D) histogram plot of band 1 vs band 4 of the above-described Landsat scene. Included are pixels of the determined training areas. In this plot, a maximum of pixels can be detected at high reflectances of both bands. A second maximum is located at the low reflectances of both bands.

Area A represents open water, B represents snow-covered ice and $C$ and $D$ represent two types of melt ponds. It can be observed that the main quantity of the pixels, including classes $A$ and $B$, lies on a main axis. The values are highly correlated between the two bands on this main axis; they represent the first principal component. As well as the principal component, some pixels form another cluster: the values in band 4 are lower than their corresponding values in band 1. They describe pixels with an included melt-pond fraction and represent the second principal component. Classes C and D can therefore be found in this cluster.

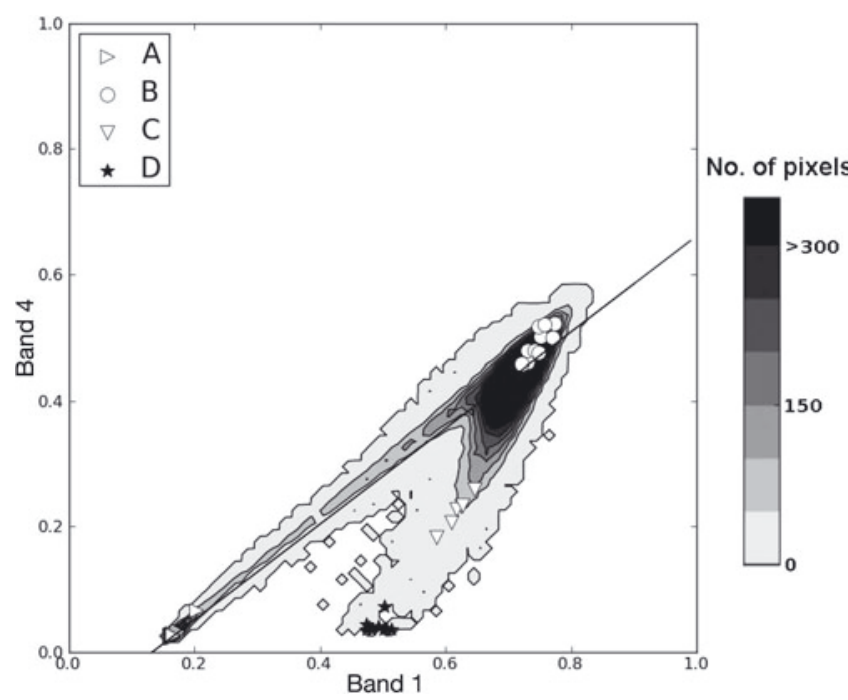

Fig. 4. 2-D histogram of Landsat reflectivities of band 1 vs band 4 for the selected scene. A-D represent the training areas for open water, snow-covered ice and melt ponds (see Fig. 2a).

To separate the pixels with a melt-pond fraction from the pixels that only have a snow and water signature, PCA is applied. First, the mean vector of the first principal component $\left(g_{1}\right)$ and a rotation matrix must be defined. The second principal component $\left(g_{2}\right)$ is perpendicular to $g_{1}$. Generally, $g_{1}$ is evaluated from all pixels of the dataset; for this analysis, however, the mean vector is defined only for the main axis (open-water/ice pixels) using the two maxima in the 2-D histogram plot (Fig. 4).

The mean vector can be described with the linear equation

$$
f(x)=m x+b,
$$

where $m$ is the slope and $b$ the offset. The rotation matrix is defined:

$$
R=\left[\begin{array}{cc}
\cos \gamma & -\sin \gamma \\
\sin \gamma & \cos \gamma
\end{array}\right]
$$

where

$$
\gamma=-\arctan m
$$

The individual components $g_{1}$ and $g_{2}$ (also called eigenvectors) describe the principal component axis of the original coordinate system. After the transformation matrix is applied, the pixels are positioned in a new coordinate system where the eigenvectors $g_{1}$ and $g_{2}$ become the new axes $G_{1}$ and $G_{2}$ (Fig. 5). The data now exhibit no discernible correlation between the main axis and the cluster of melt ponds. Furthermore, the transformed dataset allows discrimination of the water-ice axis and the cluster.

A threshold to separate the water/ice pixels from the meltpond pixels is defined. This runs parallel to the open-water/ ice axis and is defined as:

$$
G_{1}<0.2 \text { and } G_{2}=\max \left(G_{2}\right) .
$$

For the analysed Landsat subset, the threshold value is set as $G_{2}=0.3$. All pixels greater than the given threshold will be assigned as pixels containing melt ponds (melt-pond pixels).

In the present case, melt-pond areas are very well developed and it can be assumed that at least one pixel contains $100 \%$ melt pond. All other pixels are only 


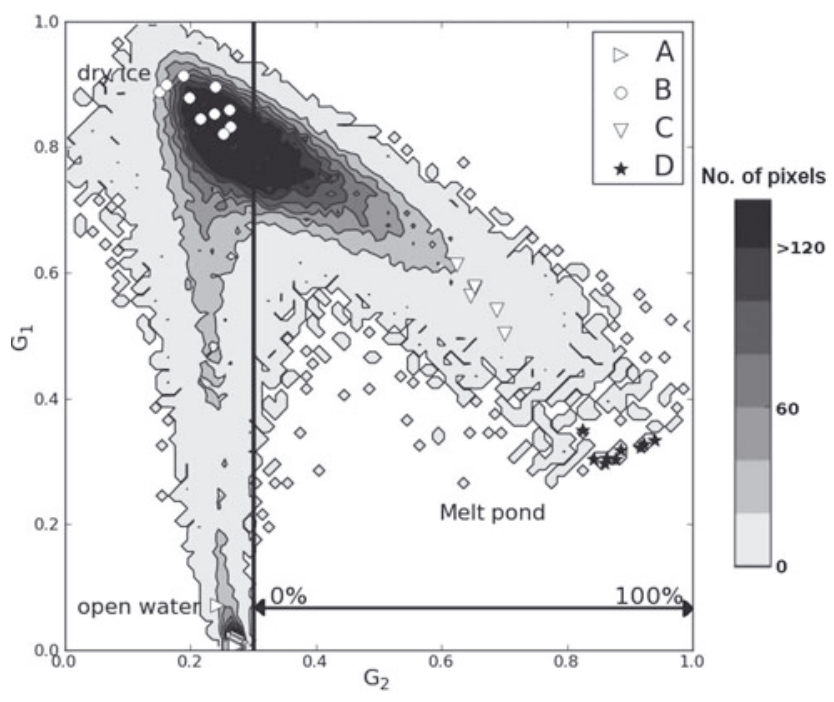

Fig. 5. Transformed new coordinate system with axes $G_{2}$ and $G_{1}$. A-D represent the training areas for open water, snow-covered ice and two types of melt ponds (see Fig. 2a).

fractionally ponded. The melt-pond pixels are scaled between $0 \%$ and $100 \%$ (Fig. 5).

To determine the melt-pond fraction (the fraction of ponds on the sea ice), the open-water area needs to be defined and subtracted from the overall area. To determine the open-water area in Landsat data, a threshold technique was applied as described by Steffen and Schweiger (1991) and Cavalieri and others (2006).

For the error estimation, we selected all mixed pixels at the border of open water and the ice edge and assigned them $50 \%$ misclassification. This led to an error of $\pm 0.35 \%$ for the open-water area for this subset.

\section{RESULTS}

The results from the classification method based on PCA are depicted in Figure 2b. Comparison of the melt-pond fraction with the true-colour composite shows good agreement.

Melt ponds cover $106.3 \pm 23.9 \mathrm{~km}^{2}$ of a total sea-ice area of $623.2 \mathrm{~km}^{2} \pm 2.2 \mathrm{~km}^{2}$; this is $17.1 \pm 3.8 \%$ of the sea-ice area.

Markus and others (2002, 2003) showed that the differences between spectral bands 2 and 3 of the Landsat 7 ETM+ sensor can also be used to detect melt ponds. They discovered that differences between bands 2 and $3\left(\Delta_{23}=\alpha_{\mathrm{b} 2}-\alpha_{\mathrm{b} 3}\right)$ above a certain threshold can be classified as ponded area. Values below this threshold can be determined as open water and unponded ice areas.

To separate between open water and ice, the information from band $1\left(\alpha_{\mathrm{b} 1}\right)$ is used. The high values are classified as ice and the low values as water. For our Landsat 7 subset, $\Delta_{23}$ is plotted against $\alpha_{\mathrm{b} 1}$ and the scatter plot is divided into three regions using the following threshold and tie points: $\Delta_{23}=0.06$ separates melt ponds from open water/ice; additionally, $\alpha_{\mathrm{b} 1}=0.16$ is defined as $100 \%$ open water and $\alpha_{\mathrm{b} 1}=0.82$ as $100 \%$ ice. If $\Delta_{23} \geq 0.06$ and $\alpha_{\mathrm{b} 1}=0.45$, the pixel is $100 \%$ melt pond (Fig. 6).

Figure 2c depicts the results of the classification using the method of Markus and others (2003). The melt-pond fraction conforms with the results of PCA and the true-colour composite. The coefficient of determination is $r^{2}=0.94$.

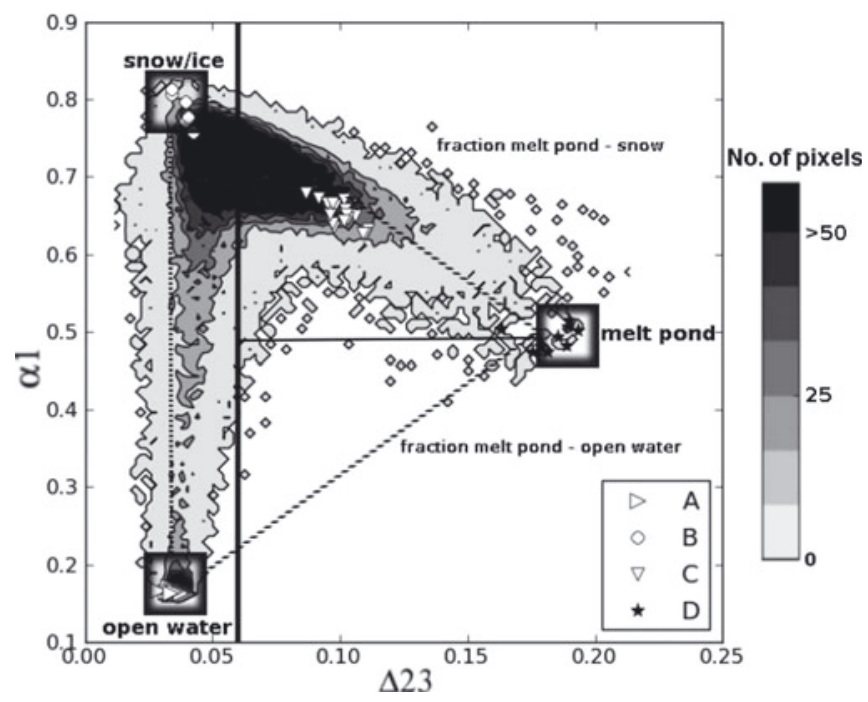

Fig. 6. The tie-point method for classifying Landsat images (after Markus and others, 2003). A-D show the training areas for open water, snow-covered ice and melt ponds (see Fig. 2a).

Melt ponds cover $88.8 \pm 10.6 \mathrm{~km}^{2}$ of a total sea-ice area of $23.2 \pm 2.2 \mathrm{~km}^{2}$; this is $14.3 \pm 3.3 \%$ of the sea-ice area.

Note from Figure 2e that the results show differences in the spatial distribution of the melt ponds. In areas with an apparently high melt-pond fraction, the results of the method developed by Markus and others (2003) give lower values than for PCA (red areas). By contrast, in areas with a lower melt-pond fraction, the method of Markus and others yields higher values (blue areas). The blue pixels in the difference plot (Fig. 2e, right) represent the greyish pixels in the true-colour subset (Fig. 2e, left).

The threshold in this analysis which divides pixels into ponded and unponded sea ice is the input parameter. The uncertainty of this method is mainly defined by the threshold value $G_{2}=0.3$. The threshold in this procedure is dependent upon the solar zenith angle, the geographical latitude and subsequent spectral reflectance of the surface, and must be defined for each satellite scene. It is therefore important to investigate how sensitive the results are to a variation of $G_{2}$ and $\Delta_{23}$ by $\pm 1 \%$ and $\pm 5 \%$ for the method of Markus and others (2003).

For $G_{2}= \pm 1 \%$ and $\pm 5 \%$, the total melt-pond area varies by $4.75 \%$ and $22.45 \%$, respectively. The linear increase of the error in both procedures shows that the distribution of the melt-pond fraction is in this case uniform. The calculated errors for the PCA method are about $0.5 \%$ lower than for the method of Markus and others (2003). The lower values for the PCA method are due to a better-defined intersection for the separation of the melt-pond fraction and the snow/water fraction. It can be seen from Figure 6 that the ice/open-water axis is not exactly parallel to the threshold. This effect causes the slightly more diffuse intersection between the two fractions.

Tests in the full Landsat scene implied that a variation of $\pm 5 \%$ for the threshold is realistic. This value was therefore used for the error calculation.

Tschudi and others (2008) describe a technique which uses a set of linear equations to analyse MODIS data in order to estimate different fractions for each pixel of a MODIS scene. Given the relatively coarse resolution of the MODIS sensor, we can assume that each MODIS pixel could contain 
Table 1. Spectral reflectances, $r_{i}$, of ice types used in the pond algorithm over the MODIS channels

\begin{tabular}{lccccc}
\hline $\begin{array}{l}\text { MODIS } \\
\text { channel }\end{array}$ & Bandwidth & Resolution & \multicolumn{2}{c}{ Surface reflectance, $r_{i}$} \\
& & & Pond & Snow/ice & $\begin{array}{c}\text { Open } \\
\text { water }\end{array}$ \\
& & & & & \\
& $\mathrm{nm}$ & $\mathrm{m}$ & & & \\
\hline 1 & $459-479$ & 500 & 0.54 & 0.80 & 0.18 \\
3 & $620-670$ & 250 & 0.26 & 0.72 & 0.06 \\
4 & $841-876$ & 250 & 0.13 & 0.67 & 0.03 \\
\hline
\end{tabular}

open water, ice and melt ponds.

$$
\left[\sum a_{i} r_{i}=R\right]_{k} \text { where } \sum a_{i}=1,
$$

where $R$ is the reflectance, $a_{i}$ are the fractional coverages for each MODIS pixel for band $k(k=1,3,4)$ and $r_{i}$ are the spectral reflectances of each surface type.

Since linear equations do not always give a definite result, we introduced a condition to restrict the interval of the solution between 0 and 1 . This also avoids negative values for the different classes.

The surface types determined in the Landsat 7 ETM+ scene are used for the classification. The spectral reflectance values for each surface type, $r_{i}$, also evaluated from this Landsat scene, are listed in Table 1.

For their analysis, Tschudi and others (2008) use an atmospheric-corrected MODIS surface-reflectance product (MOD09). For better comparison of the results from the MODIS subset with the Landsat scene, however, bands 1, 3 and 4 from the MODIS Level 1B product are used here.

Figure $2 \mathrm{~d}$ depicts the result of the classification using the method introduced by Tschudi and others (2008). The maximum error for this method is $\sim 10 \%$. Melt ponds cover $183.9 \pm 18.4 \mathrm{~km}^{2}$ of a total sea-ice area of $587.8 \pm 58.8$ $\mathrm{km}^{2}$; this is $29.4 \pm 2.9 \%$ of the sea-ice area.

\section{DISCUSSION}

Table 2 lists the results of the calculated melt-pond fraction from three different methods and two different datasets. The Landsat methods are consistent. The main difference appears in the comparison of the Landsat methods with the MODIS classification. The melt-pond fraction is clearly higher for the MODIS classification than for both Landsat classifications. This behaviour has been described by Tschudi and others (2008).

From examination of the MODIS classification (Fig. $2 d$ and e), we note that the results over sea-ice areas are consistent but that a misclassification occurs at the border with open-water areas. Instead of a water and a snow/ice fraction, the algorithm detects a very high melt-pond fraction and a very low snow/ice fraction. This needs to be investigated in detail in the future.

The differences between the two Landsat methods could result from the fact that three spectral bands (bands 1-3) are used by Markus and others (2003). They only cover the short wavelength range of the spectral reflectances of the surface features. For the PCA method, only bands 1 and 4 are used.
Table 2. Comparison of melt-pond coverage results

\begin{tabular}{lccc}
\hline & PCA & Markus & MODIS \\
\hline Coverage $\left(\mathrm{km}^{2}\right)$ & $106.3 \pm 23.9$ & $88.8 \pm 10.6$ & $183.9 \pm 18.4$ \\
$\%$ & $17.1 \pm 3.8$ & $14.3 \pm 3.3$ & $29.4 \pm 2.9$ \\
\hline
\end{tabular}

Band 4 utilizes the advantage of the larger spectral differences between melt ponds and ice or snow cover. In addition, the method of Markus and others (2003) needs more manual input than the PCA method, because tie points for each fraction must be defined for each satellite scene. For the PCA method, only the thresholds that span the meltpond fraction need to be defined.

\section{CONCLUSION}

Very high-resolution satellite data can be used to determine melting features on Arctic sea ice. The limitations are many, however. An extensive search of the USGS archive for suitable Landsat scenes results in only a few usable images. On closer inspection of the data, it became clear that nearly all scenes that contain melt ponds have problems with saturated pixels. Saturation is related to sun elevation and the surface type. Unfortunately, melt-pond development increases when the sun elevation is high. There are procedures to interpolate between the saturated and unsaturated bands, but they could not be easily applied since the different spectral behaviour of the surface types has to be incorporated. Other disadvantages are the revisit time of 16 days and the fact that the Arctic is an area with an above-average proportion of cloudy days.

The above-listed points demonstrate that very highresolution satellite data can be used to detect melt ponds or provide a basis for comparison with lower-resolution satellite data, but not as the only source for a seasonal meltpond dataset over the entire Arctic. Lower-resolution sensors such as MODIS obtain a full coverage of the area on a daily basis. To acquire a melt-pond dataset of the entire Arctic, a combination of high- and medium-resolution sensors is recommended.

\section{ACKNOWLEDGEMENTS}

We thank the scientific editor and the two reviewers for their sound comments and suggestions. The International Max Planck Research School for Maritime Affairs, Hamburg, funded this study. Additional support was provided by the Cluster of Excellence CliSAP (EXC177), University of Hamburg, funded through the German Science Foundation (DFG).

\section{REFERENCES}

Bindschadler, R. and 8 others. 2008. The Landsat image mosaic of Antarctica. Remote Sens. Environ., 112(12), 4214-4226.

Cavalieri, D.J., T. Markus, D.K. Hall, A.J. Gasiewski, M. Klein and A. Ivanoff. 2006. Assessment of EOS Aqua AMSR-E Arctic sea ice concentrations using Landsat-7 and airborne microwave imagery. IEEE Trans. Geosci. Remote Sens., 44(1), 3057-3069. 
Curry, J.A., J.L. Schramm and E.E. Ebert. 1995. Sea ice-albedo climate feedback mechanism. J. Climate, 8(2), 240-247.

Fetterer, F. and N. Untersteiner. 1998. Observations of melt ponds on Arctic sea ice. J. Geophys. Res., 103(C11), 24,821-24,835.

Grenfell, T.C. and G.A. Maykut. 1977. The optical properties of ice and snow in the Arctic Basin. J. Glaciol., 18(80), 445-463.

Markus, T., D.J. Cavalieri and A. Ivanoff. 2002. The potential of using Landsat 7 ETM+ for the classification of sea-ice surface conditions during summer. Ann. Glaciol., 34, 415-419.

Markus, T., D.J. Cavalieri, M.A. Tschudi and A. Ivanoff. 2003. Comparison of aerial video and Landsat 7 data over ponded sea ice. Remote Sens. Environ., 86(4), 458-469.

Morassutti, M.P. and E.F. LeDrew. 1996. Albedo and depth of melt ponds on sea ice. Int. J. Climatol., 16(7), 817-838.

Perovich, D.K. 1996. The optical properties of sea ice. CRREL Monogr., 96(1), 1-25.

Perovich, D.K. and W.B. Tucker, III. 1997. Arctic sea-ice conditions and the distribution of solar radiation during summer. Ann. Glaciol., 25, 445-450.

Perovich, D.K., W.B. Tucker, III and K.A. Ligett. 2002a. Aerial observations of the evolution of ice surface conditions during summer. J. Geophys. Res., 107(C10), 8048. (10.1029/ 2000JC000449.)
Perovich, D.K., T.C. Grenfell, B. Light and P.V. Hobbs. 2002b. Seasonal evolution of the albedo of multiyear Arctic sea ice. J. Geophys. Res., 107(C10), 8044. (10.1029/2000JC000438.)

Perovich, D.K. and 7 others. 2009. Transpolar observations of the morphological properties of Arctic sea ice. J. Geophys. Res., 114, C00A04. (10.1029/2008JC004892.)

Steffen, K. and A. Schweiger. 1991. NASA team algorithm for sea ice concentration retrieval from Defense Meteorological Satellite Program special sensor microwave imager: comparison with Landsat satellite imagery. J. Geophys. Res., 96(C12), 21,971-21,987.

Tschudi, M.A., J.A. Curry and J.A. Maslanik. 1997. Determination of areal surface-feature coverage in the Beaufort Sea using aircraft video data. Ann. Glaciol., 25, 434-438.

Tschudi, M.A., J.A. Curry and J.A. Maslanik. 2001. Airborne observations of summertime surface features and their effect on surface albedo during FIRE/SHEBA. J. Geophys. Res., 106(D14), 15,335-15,344.

Tschudi, M.A., J.A. Maslanik and D.K. Perovich. 2008. Derivation of melt pond coverage on Arctic sea ice using MODIS observations. Remote Sens. Environ., 112(5), 2605-2614.

Warren, S.G. 1982. Optical properties of snow. Rev. Geophys., 20(1), 67-89. 